Pacific Journal of Mathematics

MIXED ARITHMETIC AND GEOMETRIC MEANS

Robert K. MEANY AND Stuart ALAN NeLson 


\title{
MIXED ARITHMETIC AND GEOMETRIC MEANS
}

\author{
B. C. Carlson, R. K. Meany, and S. A. Nelson
}

Consider all ordinary arithmetic and geometric means of $n$ real nonnegative numbers taken $k$ at a time. Let $\alpha_{k}$ be the geometric mean of all the arithmetic means and $\gamma_{k}$ the arithmetic mean of all the geometric means. It is proved that $\alpha_{k}$ increases with $k, \gamma_{k}$ decreases, and $\gamma_{h} \leqq \alpha_{k}$ if $h+k>n$. These results are generalized to mixed means of any real orders. Comparison of $\alpha_{k}$ and $\gamma_{k}$ with elementary symmetric functions suggests a conjecture.

1. Introduction and summary. If $x, y, z$ are real nonnegative numbers, then [2], [3]

$$
\frac{1}{3}\left[(x y)^{1 / 2}+(x z)^{1 / 2}+(y z)^{1 / 2}\right] \leqq\left[\frac{x+y}{2} \frac{x+z}{2} \frac{y+z}{2}\right]^{1 / 3} .
$$

The inequality was proved originally to demonstrate that the righthand side is the better approximation to the capacity of an ellipsoid with semiaxes $x, y, z$. To generalize (1.1) from three to $n$ variables, $n \geqq 3$, consider the real nonnegative numbers $x_{1}, x_{2}, \cdots, x_{n}$ and form all ordinary (as opposed to weighted) arithmetric and geometric means of these numbers taken $n-1$ at a time. Then the arithmetic mean of the geometric means does not exceed the geometric mean of the arithmetic means [3], [4].

In the present note we consider arithmetic and geometric means of $x_{1}, \cdots, x_{n}$ taken $k$ at a time, $k=1,2, \cdots, n$. Let $\alpha_{k}$ denote the geometric mean of the arithmetic means, and $\gamma_{k}$ the arithmetic mean of the geometric means. For example, if $n=4$, we have

$$
\begin{aligned}
& \alpha_{2}=\left[\frac{x_{1}+x_{2}}{2} \frac{x_{1}+x_{3}}{2} \frac{x_{1}+x_{4}}{2} \frac{x_{2}+x_{3}}{2} \frac{x_{2}+x_{4}}{2} \frac{x_{3}+x_{4}}{2}\right]^{1 / 6}, \\
& \gamma_{3}=\frac{1}{4}\left[\left(x_{1} x_{2} x_{3}\right)^{1 / 3}+\left(x_{1} x_{2} x_{4}\right)^{1 / 3}+\left(x_{1} x_{3} x_{4}\right)^{1 / 3}+\left(x_{2} x_{3} x_{4}\right)^{1 / 3}\right] .
\end{aligned}
$$

Note that $\alpha_{n}=\gamma_{1}$ is the arithmetic mean of $x_{1}, \cdots, x_{n}$, and $\alpha_{1}=\gamma_{n}$ is the geometric mean. We shall show first (Theorem 1) that $\alpha_{k}$ increases with $k$ while $\gamma_{k}$ decreases. The second result (Theorem 2) states that $\gamma_{h} \leqq \alpha_{k}$ if $h+k>n$. If $n=3$, for instance, we have $\gamma_{2} \leqq \alpha_{2}$, which is (1.1), and if $n=4$, as in (1.2), we have $\gamma_{3} \leqq \alpha_{2}$. The case $h=k=n$ is the ordinary inequality of the arithmetic and geometric means, and the case $h=k=n-1, n>2$, is the inequality stated in [3].

More generally we shall define a mixed mean $M_{s t}(k)$ of the real 
nonnegative numbers $x_{1}, \cdots, x_{n}$ taken $k$ at a time. As $k$ increases from 1 to $n, M_{s t}(k)$ increases or decreases monotonically, according as $s<t$ or $s>t$, from the mean of order $s$ of $x_{1}, \cdots x_{n}$ to the mean of order $t$. If $s \leqq t$ and $h+k>n$, then $M_{t s}(h) \leqq M_{s t}(k)$.

Maclaurin's theorem for the elementary symmetric functions $p_{1}, \cdots, p_{n}$ suggests allowing $s$ or $t$ to depend on $k$, as in $M_{k 0}(k)=p_{k}^{1 / k}$. The inequality $\gamma_{k} \leqq p_{k}^{1 / k}$ is very easy to prove, and it is conjectured that $p_{h}^{1 / h} \leqq \alpha_{k}$ if $h+k>n$.

2. Monotony. We first define $\alpha_{k}$ and $\gamma_{k}$ and then show that each is monotonic in $k$.

Definition 1. If $V=\left\{y_{1}, y_{2}, \cdots, y_{k}\right\}$, where $k \geqq 1$ and $y_{1}, \cdots, y_{k}$ are real nonnegative numbers, we define $A(V)$ and $G(V)$ to be the arithmetic and geometric means of the elements of $V$ :

$$
A(V)=\frac{1}{k}\left(y_{1}+\cdots+y_{k}\right), \quad G(V)=\left(y_{1} \cdots y_{k}\right)^{1 / k} .
$$

Definition 2. Let $x_{1}, \cdots, x_{n}$ be real nonnegative numbers and let $k$ be a positive integer not exceeding $n$. The subsets of $\left\{x_{1}, \cdots, x_{n}\right\}$ with cardinal number $k$ will be denoted by $V_{1}, V_{2}, \cdots, V_{v}$, where $v=\left(\begin{array}{c}n \\ k\end{array}\right)$. We define

$$
\alpha_{k}=\left[\prod_{i=1}^{v} A\left(V_{i}\right)\right]^{1 / v}, \quad \gamma_{k}=\frac{1}{v} \sum_{i=1}^{v} G\left(V_{i}\right) .
$$

THEOREM 1. Let $x_{1}, \cdots, x_{n}$ be real nonnegative numbers and let the means $\alpha_{1}, \cdots, \alpha_{n}$ and $\gamma_{1}, \cdots, \gamma_{n}$ be defined by Definition 2. Then $\alpha_{k-1} \leqq \alpha_{k}, k=2,3, \cdots, n$, with strict inequality unless either (1) $x_{1}=x_{2}=\cdots=x_{n}$ or (2) $k$ of the $x_{i}$ are zero. Also, $\gamma_{k-1} \geqq \gamma_{k}, k=$ $2,3, \cdots, n$, with strict inequality unless either (1) $x_{1}=x_{2}=\cdots=x_{n}$ or (2) $n-k+2$ of the $x_{i}$ are zero.

Proof. Let $W_{1}, W_{2}, \cdots, W_{w}, w=\left(\begin{array}{c}n \\ k-1\end{array}\right)$, be the subsets of $\left\{x_{1}, \cdots, x_{n}\right\}$ with cardinal number $k-1$. Also, let $V_{i}, i=1, \cdots, v$, be defined by Definition 2 and let the subsets of $V_{i}$ with cardinal number $k-1$ be denoted by $V_{i 1}, \cdots, V_{i k}$. Then each set $V_{i j}$ equals one of the sets $W_{1}, \cdots, W_{w}$, and each of the $W_{i}$ occurs exactly $n-k+1$ times among the sets $V_{11}, \cdots, V_{v k}$. Note that $w(n-k+1)=v k$.

Using the inequality of the arithmetic and geometric means, we have 


$$
A\left(V_{i}\right)=\frac{1}{k} \sum_{j=1}^{k} A\left(V_{i j}\right) \geqq\left[\prod_{j=1}^{k} A\left(V_{i j}\right)\right]^{1 / k}, \quad i=1 . \cdots, v,
$$

with strict inequality unless all the elements of $V_{i}$ are equal. Hence there is strict inequality for some value of $i$ unless $x_{1}=x_{2}=\cdots=x_{n}$. It follows that

$$
\alpha_{k}=\left[\prod_{i=1}^{v} A\left(V_{i}\right)\right]^{1 / v} \geqq\left[\prod_{i=1}^{v} \prod_{j=1}^{k} A\left(V_{i j}\right)\right]^{1 / v k},
$$

with strict inequality unless either $(1) x_{1}=x_{2}=\cdots=x_{n}$ or (2) $k$ of the $x_{i}$ are zero (with the result that $A\left(V_{i}\right)=0$ for some value of $i$ ). The third member of (2.4) equals

$$
\left[\prod_{j=1}^{w} A\left(W_{i}\right)\right]^{(n-k+1) / v k}=\left[\prod_{i=1}^{w} A\left(W_{i}\right)\right]^{1 / w}=\alpha_{k-1} .
$$

Similarly we have

$$
G\left(V_{i}\right)=\left[\prod_{j=1}^{k} G\left(V_{i j}\right)\right]^{1 / k} \leqq \frac{1}{k} \sum_{j=1}^{k} G\left(V_{i j}\right), \quad i=1, \cdots, v,
$$

with strict inequality unless either (i) all the elements of $V_{i}$ are equal or (ii) two elements of $V_{i}$ are zero. Hence there is strict inequality for some value of $i$ unless either (1) $x_{1}=x_{2}=\cdots=x_{n}$ or (2) $n-k+2$ of the $x_{i}$ are zero (with the result that two elements of $V_{i}$ are zero for each value of $i$ ). It now follows that

$$
\gamma_{k}=\frac{1}{v} \sum_{i=1}^{v} G\left(V_{i}\right) \leqq \frac{1}{v k} \sum_{i=1}^{v} \sum_{j=1}^{k} G\left(V_{i j}\right),
$$

with strict inequality unless (1) or (2) holds. The third member of (2.7) equals

$$
\frac{n-k+1}{v k} \sum_{i=1}^{w} G\left(W_{i}\right)=\frac{1}{w} \sum_{i=1}^{w} G\left(W_{i}\right)=\gamma_{k-1} .
$$

3. Inequality of mixed means. Let $V_{1}, V_{2}, \cdots, V_{v}, v=\left(\begin{array}{l}n \\ k\end{array}\right)$, be defined by Definition 2, and similarly denote the subsets of $\left\{x_{1}, \cdots, x_{n}\right\}$ with cardinal number $h$ by $U_{1}, U_{2}, \cdots, U_{u}, u=\left(\begin{array}{l}n \\ h\end{array}\right)$.

Lemma 1. If $h+k>n$, then

$$
\begin{array}{ll}
\frac{1}{u} \sum_{i=1}^{u} A\left(U_{i} \cap V_{j}\right)=A\left(V_{j}\right), & j=1, \cdots, v, \\
{\left[\prod_{j=1}^{v} G\left(U_{i} \cap V_{j}\right)\right]^{1 / v}=G\left(U_{i}\right),} & i=1, \cdots, u .
\end{array}
$$


Proof. The condition $h+k>n$ implies that $U_{i} \cap V_{j}$ is nonvoid for all $i$ and $j$. Each term on the left side of (3.1) is a linear combination of the elements of $V_{j}$, and so is the sum. Since the summation extends over all subsets $U_{i}$ with cardinal number $h$, the sum is unchanged by permuting the elements of $V_{j}$ and must therefore be a constant multiple of $A\left(V_{j}\right)$. The multiplier is determined to be unity by choosing all the $x_{i}$ to be equal.

Each factor on the left side of (3.2) is a product of powers of the elements of $U_{i}$, and so is the product of the factors. Since there is one factor for every subset $V_{j}$ with cardinal number $k$, the product is unchanged by permuting the elements of $U_{i}$ and must therefore be a power of $G\left(U_{i}\right)$. The power is determined to be unity by choosing all the $x_{i}$ to be equal.

THEOREM 2. Let $x_{1}, \cdots, x_{n}$ be real nonnegative numbers and let the means $\alpha_{1}, \cdots, \alpha_{n}$ and $\gamma_{1}, \cdots, \gamma_{n}$ be defined by Definition 2. Then $\gamma_{h} \leqq \alpha_{k}$ if $h+k>n$. The inequality is strict unless either (1) $(h-1)(k-1)=0$ or $(2) x_{1}=x_{2}=\cdots=x_{n}$ or (3) $k$ of the $x_{i}$ are zero.

Proof. One form of Hölder's inequality states that if $(a),(b), \cdots,(s)$ are $u$-tuples of real nonnegative numbers and $\alpha, \beta, \cdots, \sigma$ are positive weights with $\alpha+\beta+\cdots+\sigma=1$, then [5, p. 22]

$$
\sum_{i=1}^{u} a_{i}^{\alpha} b_{i}^{\beta} \cdots s_{i}^{\sigma} \leqq\left(\sum_{i=1}^{u} a_{i}\right)^{\alpha}\left(\sum_{i=1}^{u} b_{i}\right)^{\beta} \cdots\left(\sum_{i=1}^{u} s_{i}\right)^{o} \cdot
$$

(The proof of this inequality consists in dividing each term on the left side by the right side and using the inequality of the arithmetic and geometric means.) Let $U_{1}, \cdots, U_{u}$ and $V_{1}, \cdots, V_{v}$ have the same meaning as in Lemma 1 , assume $h+k>n$, and introduce the abbreviations

$$
G_{i}=G\left(U_{i}\right), A_{j}=A\left(V_{j}\right), G_{i j}=G\left(U_{i} \cap V_{j}\right), A_{i j}=A\left(U_{i} \cap V_{j}\right) .
$$

We now choose

$$
\left[\begin{array}{ccc}
a_{1} & \cdots & s_{1} \\
\vdots & & \vdots \\
a_{u} & \cdots & s_{u}
\end{array}\right]=\left[\begin{array}{ccc}
G_{11} & \cdots & G_{1 v} \\
\vdots & & \vdots \\
G_{u 1} & \cdots & G_{u v}
\end{array}\right]
$$

and put $\alpha=\beta=\cdots=\sigma=1 / v$. Hölder's inequality becomes

$$
\sum_{i=1}^{u} G_{i}=\sum_{i=1}^{u} \prod_{j=1}^{v} G_{i j}^{1 / v} \leqq \prod_{j=1}^{v}\left(\sum_{i=1}^{u} G_{i j}\right)^{1 / v}
$$

where the equality of the first two members follows from Lemma 1. The inequality of the arithmetic and geometric means implies 


$$
\sum_{i=1}^{u} G_{i j} \leqq \sum_{i=1}^{u} A_{i j}=u A_{j}, \quad j=1, \cdots, v,
$$

with strict inequality for some value of $j$ unless either $(h-1)(k-1)=0$ or (2) $x_{1}=x_{2}=\cdots=x_{n}$. The equality of the second and third members follows from Lemma 1. Hence

$$
\prod_{j=1}^{v}\left(\sum_{i=1}^{u} G_{i j}\right)^{1 / v} \leqq u \prod_{j=1}^{v} A_{j}^{1 / v}
$$

with strict inequality unless either $(1)(h-1)(k-1)=0$ or $(2)$ $x_{1}=x_{2}=\cdots=x_{n}$ or (3) $k$ of the $x_{i}$ are zero (with the result that $A_{j}=0$ for some value of $j$ ). We have finally

$$
\gamma_{h}=\frac{1}{u} \sum_{i=1}^{u} G_{i} \leqq \prod_{j=1}^{v} A_{j}^{1 / v}=\alpha_{k}, \quad h+k>n,
$$

with obvious equality if (1) or (2) or (3) holds and strict inequality otherwise.

4. Mixed means of general orders. No extension of these results to weighted means is known. However, it is not difficult to generalize the inequalities for mixed arithmetic and geometric means to mixed means of any real orders, and we shall sketch briefly what modifications are necessary. Definition 1 is augmented by defining the mean of any real order $t$,

$$
\begin{aligned}
& M_{t}(V)=\left(\frac{1}{k} \sum_{i=1}^{k} y_{i}^{t}\right)^{1 / t}, \\
& M_{0}(V)=G(V) .
\end{aligned}
$$

Note that $A(V)=M_{1}(V)$. Similarly we augment Definition 2 by defining the mixed mean of orders $s$ and $t$ of the real nonnegative numbers $x_{1}, \cdots, x_{n}$ taken $k$ at a time:

$$
\begin{array}{ll}
M_{s t}(k)=\left\{\frac{1}{v} \sum_{i=1}^{v}\left[M_{t}\left(V_{i}\right)\right]^{s}\right\}^{1 / s}, & s \neq 0, \\
M_{0 t}(k)=\left[\prod_{i=1}^{v} M_{t}\left(V_{i}\right)\right]^{1 / v} . &
\end{array}
$$

Note that $\alpha_{k}=M_{01}(k)$ and $\gamma_{k}=M_{10}(k)$. Also, $M_{s t}(1)$ is the mean of order $s$ of $x_{1}, \cdots, x_{n}$ and $M_{s t}(n)$ is the mean of order $t$. For fixed $k$, $M_{s t}(k)$ increases with $s$ and with $t$ because of a basic property of mean values [5, p. 26]. Finally, $M_{s t}(k)$ is nonzero unless either (1) $s \leqq 0, t \leqq 0$, and one of the $x_{i}$ is zero, or (2) $s \leqq 0, t>0$, and $k$ of the $x_{i}$ are zero, or (3) $s>0, t \leqq 0$, and $n-k+1$ of the $x_{i}$ are zero, or (4) $s>0, t>0$, and all the $x_{i}$ are zero. 
The generalization of Theorem 1 states that $M_{s t}(k)$ increases or decreases with increasing $k$ according as $s<t$ or $s>t$. In both cases $M_{s t}(k)$ and $M_{s t}(k-1)$ are unequal unless either (1) both are zero or (2) $x_{1}=x_{2}=\cdots=x_{n}$. If $s=t$ the mixed mean is independent of $k$ :

$$
M_{t t}(k)=\left(\frac{1}{n} \sum_{i=1}^{n} x_{i}^{t}\right)^{1 / t}, \quad k=1, \cdots, n .
$$

Here and subsequently, the cases in which $s$ or $t$ is zero are not written explicitly but may be included by agreeing that an appropriate geometric mean is intended or by taking the limit as $s \rightarrow 0$ or $t \rightarrow 0$. The proof of monotony in the general case is quite similar to the proof of Theorem 1, the extension of (2.3) being

$$
M_{t}\left(V_{i}\right)=\left\{\frac{1}{k} \sum_{j=1}^{k}\left[M_{t}\left(V_{i j}\right)\right]^{t}\right\}^{1 / t} \geqq\left\{\frac{1}{k} \sum_{j=1}^{k}\left[M_{t}\left(V_{i j}\right)\right]^{s}\right\}^{1 / s}, \quad t>s .
$$

The inequality, which is reversed if $t<s$, holds because a mean of order $s$ increases with $s[5$, p. 26].

The generalization of Lemma 1 states that

$$
\left\{\frac{1}{u} \sum_{i=1}^{u}\left[M_{t}\left(U_{i} \cap V_{j}\right)\right]^{t}\right\}^{1 / t}=M_{t}\left(V_{j}\right), \quad h+k>n .
$$

The same sequence of steps as in the proof of Theorem 2 can now be followed in the general case, with Hölder's inequality replaced by Jessen's form of Minkowski's inequality [5, p. 31] and with the inequality $G \leqq A$ in (3.7) replaced by $M_{s} \leqq M_{t}$ if $s \leqq t$. The result is

$$
M_{t s}(h) \leqq M_{s t}(k), \quad s \leqq t, h+k>n .
$$

The inequality is strict unless either (1) $s=t$ or $(2)(h-1)(k-1)=0$ or (3) $x_{1}=x_{2}=\cdots=x_{n}$ or (4) $s \leqq t \leqq 0$ and one of the $x_{i}$ is zero or (5) $s \leqq 0, t>0$, and $k$ of the $x_{i}$ are zero.

5. Comparison with elementary symmetric functions. Let $p_{k}$ denote the elementary symmetric function of degree $k$ of the real nonnegative numbers $x_{1}, \cdots, x_{n}$, multiplied by a normalizing constant to make $p_{k}=1$ if $x_{1}=\cdots=x_{n}=1$. For example, if $n=3$ and $\left(x_{1}, x_{2}, x_{3}\right)=(x, y, z)$, we have

$$
p_{1}=\frac{1}{3}(x+y+z), \quad p_{2}=\frac{1}{3}(x y+y z+z x), \quad p_{2}=x y z,
$$

and for any $n$ it follows from (4.2) that

$$
p_{k}^{1 / k}=M_{k 0}(k) \text {. }
$$


The counterpart of Theorem 1 is Maclaurin's theorem [5, p. 52], which states that $p_{k}^{1 / k}$ is a decreasing function of $k$. Let us try to compare three increasing sequences of mean values, each beginning with the geometric mean and ending with the arithmetic mean:

$$
\begin{gathered}
\alpha_{1} \leqq \alpha_{2} \leqq \cdots \leqq \alpha_{n+1-k} \leqq \cdots \leqq \alpha_{n-1} \leqq \alpha_{n} \\
p_{n}^{1 / n} \leqq p_{n-1}^{1 /(n-1)} \leqq \cdots \leqq p_{k}^{1 / k} \leqq \cdots \leqq p_{2}^{1 / 2} \leqq p_{1}, \\
\gamma_{n} \leqq \gamma_{n-1} \leqq \cdots \leqq \gamma_{k} \leqq \cdots \leqq \gamma_{2} \leqq \gamma_{1} .
\end{gathered}
$$

If $n=3$ we have $\gamma_{2} \leqq p_{2}^{1 / 2} \leqq \alpha_{2}$. The inequality of the first and third members is (1.1), the inequality of the first and second members follows at once from the inequality of the arithmetic mean and the root-mean-square, and the inequality of the second and third members is proved in several steps in [2].

For all $n$ and $k$, Theorem 2 implies $\gamma_{k} \leqq \alpha_{n+1-k}$. Also, since a mean value increases with its order $[5, \mathrm{p} .26]$ we have $M_{10}(k) \leqq M_{k 0}(k)$ and hence

$$
\gamma_{k} \leqq p_{k}^{1 / k}, \quad k=1, \cdots, n .
$$

The known results for $n=3$ suggest the conjecture that $p_{k}^{1 / k} \leqq \alpha_{n+1-k}$. In view of (5.3) it is equivalent to conjecture that $p_{h}^{1 / h} \leqq \alpha_{k}$ if $h+k>n$. Were this proved true, Theorem 2 would follow as a corollary because of (5.4).

\section{REFERENCES}

1. E. F. Beckenbach and R. Bellman, Inequalities, Springer, Berlin, 1961.

2. B. C. Carlson, Inequalities for a symmetric elliptic integral, Proc. Amer. Math. Soc., 25 (1970), 698-703.

3. - An inequality of mixed arithmetic and geometric means (Problem 70-10), SIAM Rev., 12 (1970), 287-288.

4. B. C. Carlson, R. K. Meany, and S. A. Nelson, An inequality of mixed arithmetic and geometric means (Solution of Problem 70-10 [3]), SIAM Rev., 13 (1971), 253-255.

5. G. H. Hardy, J. E. Littlewood, and G. Pólya, Inequalities, 2nd ed., Cambridge Univ. Press, Cambridge, 1952. MR 13, 727.

Received July 22, 1970. The research of the first author was supported by the Ames Laboratory of the U. S. Atomic Energy Commission.

Iowa STATE UNIVERSITY 



\section{PACIFIC JOURNAL OF MATHEMATICS}

\section{EDITORS}

\author{
H. SAMELSON \\ Stanford University \\ Stanford, California 94305 \\ C. R. HовBY \\ University of Washington \\ Seattle, Washington 98105
}

J. DUGUndis

Department of Mathematics

University of Southern California

Los Angeles, California 90007

RICHARD ARENS

University of California

Los Angeles, California 90024

\section{ASSOCIATE EDITORS}
E. F. BeCKenbaCH
B. H. NeUmanN
F. WOLF
K. YoshidA

\section{SUPPORTING INSTITUTIONS}

\author{
UNIVERSITY OF BRITISH COLUMBIA \\ CALIFORNIA INSTITUTE OF TECHNOLOGY \\ UNIVERSITY OF CALIFORNIA \\ MONTANA STATE UNIVERSITY \\ UNIVERSITY OF NEVADA \\ NEW MEXICO STATE UNIVERSITY \\ OREGON STATE UNIVERSITY \\ UNIVERSITY OF OREGON \\ OSAKA UNIVERSITY \\ UNIVERSITY OF SOUTHERN CALIFORNIA
}

\author{
STANFORD UNIVERSITY \\ UNIVERSITY OF TOKYO \\ UNIVERSITY OF UTAH \\ WASHINGTON STATE UNIVERSITY \\ UNIVERSITY OF WASHINGTON

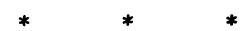 \\ AMERICAN MATHEMATICAL SOCIETY \\ CHEVRON RESEARCH CORPORATION \\ NAVAL WEAPONS CENTER
}

The Supporting Institutions listed above contribute to the cost of publication of this Journal, but they are not owners or publishers and have no responsibility for its content or policies.

Mathematical papers intended for publication in the Pacific Journal of Mathematics should be in typed form or offset-reproduced, (not dittoed), double spaced with large margins. Underline Greek letters in red, German in green, and script in blue. The first paragraph or two must be capable of being used separately as a synopsis of the entire paper. The editorial "we" must not be used in the synopsis, and items of the bibliography should not be cited there unless absolutely necessary, in which case they must be identified by author and Journal, rather than by item number. Manuscripts, in duplicate if possible, may be sent to any one of the four editors. Please classify according to the scheme of Math. Rev. Index to Vol. 39. All other communications to the editors should be addressed to the managing editor, Richard Arens, University of California, Los Angeles, California, 90024.

50 reprints are provided free for each article; additional copies may be obtained at cost in multiples of 50 .

The Pacific Journal of Mathematics is published monthly. Effective with Volume 16 the price per volume (3 numbers) is $\$ 8.00$; single issues, $\$ 3.00$. Special price for current issues to individual faculty members of supporting institutions and to individual members of the American Mathematical Society: $\$ 4.00$ per volume; single issues $\$ 1.50$. Back numbers are available.

Subscriptions, orders for back numbers, and changes of address should be sent to Pacific Journal of Mathematics, 103 Highland Boulevard, Berkeley, California, 94708.

PUBLISHED BY PACIFIC JOURNAL OF MATHEMATICS, A NON-PROFIT CORPORATION

Printed at Kokusai Bunken Insatsusha (International Academic Printing Co., Ltd.), 7-17, Fujimi 2-chome, Chiyoda-ku, Tokyo, Japan. 


\section{Pacific Journal of Mathematics}

Vol. 38, No. $2 \quad$ April, 1971

Richard Davis Anderson and Thomas Ashland Chapman, Extending

homeomorphisms to Hilbert cube manifolds .................. 281

Nguyen Huu Anh, Restriction of the principal series of $\operatorname{SL}(n, \mathbf{C})$ to some

reductive subgroups................................ 295

David W. Boyd, Indices for the Orlicz spaces . . . . . . . . . . . . 315

William Garfield Bridges, The polynomial of a non-regular digraph ...... 325

Billie Chandler Carlson, Robert K. Meany and Stuart Alan Nelson, Mixed

arithmetic and geometric means........................ 343

H. A. Çelik, Commutative associative rings and anti-flexible rings ...... 351

Hsin Chu, On the structure of almost periodic transformation groups ...... 359

David Allyn Drake, The translation groups of n-uniform translation

Hjelmslev planes ................................ 365

Michael Benton Freeman, The polynomial hull of a thin two-manifold . . . . 377

Anthony Alfred Gioia and Donald Goldsmith, Convolutions of arithmetic

functions over cohesive basic sequences .................... 391

Leslie C. Glaser, A proof of the most general polyhedral Schoenflies

conjecture possible ................................

Thomas Lee Hayden and Ted Joe Suffridge, Biholomorphic maps in Hilbert

space have a fixed point ................................ 419

Roger Alan Horn, Schlicht mappings and infinitely divisible kernels ...... 423

Norman Ray Howes, On completeness ...................... 431

Hideo Imai, Sario potentials on Riemannian spaces................ 441

A. A. Iskander, Subalgebra systems of powers of partial universal

algebras.

Barry E. Johnson, Norms of derivations of $\mathscr{L}(\mathrm{X})$.

David Clifford Kay and Eugene W. Womble, Axiomatic convexity theory and relationships between the Carathéodory, Helly, and Radon numbers

Constantine G. Lascarides, A study of certain sequence spaces of Maddox

and a generalization of a theorem of Iyer .............

C. N. Linden, On Blaschke products of restricted growth .

John S. Lowndes, Some triple integral equations ................. 515

Declan McCartan, Bicontinuous preordered topological spaces ......... 523

S. Moedomo and J. Jerry Uhl, Jr., Radon-Nikodým theorems for the Bochner and Pettis integrals ...

Calvin Cooper Moore and Joseph Albert Wolf, Totally real representations

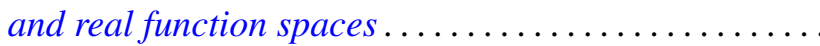

Reese Trego Prosser, A form of the moment problem for Lie groups. ... 